Journal of

Cardiology and Vascular Medicine

\title{
A Rare Case of Hypertrophic Cardiomyopathy Associated with Congenital Mitral Stenosis
}

\author{
Bindia Id, Sangare Z, Diop Ib, Regnault K, Mingou Js*, Dioum M, Sarr Em, Leye M, Manga S, Dieye O, Diagne A, Diene L \\ Cardiology Department, Aristide Le Dantec Hospital University, Dakar, Senegal
}

*Corresponding author: Joseph Salvador Mingou, Cardiology Department, Aristide Le Dantec Hospital University, Dakar, Senegal, Email: mingoujoseph@gmail.com

Received Date: February 02, 2019; Accepted Date: March 05, 2019; Published Date: March 07, 2019

Citation: Bindia Id (2019) A Rare Case of Hypertrophic Cardiomyopathy Associated with Congenital Mitral Stenosis. J Cardio Vasc Med 5: 1-4.

\section{Summary}

Hypertrophic obstructive cardiomyopathy is mostly associated with mitral insufficiency rather than mitral stenosis. This association is very rare and no cases have been reported in Africa. Our case was about 22-months-old female that was referred with one year history of tachypnea and III to IV class of dyspnea. Transthoracic echocardiography showed serious mitral stenosis and a mean gradient of $27 \mathrm{mmHg}$. The inter-ventricular septum was hypertrophic with a width of $8.5 \mathrm{~mm}$ with small aortic annulus leading sub aortic stenosis with a mean gradient of $73 \mathrm{mmHg}$. There was also a severe pulmonary hypertension at 79 $\mathrm{mmHg}$. It was expected to doing a standard septal myectomy and mitral valve replacement.

Keywords: Hypertrophic cardiomyopathy, mitral stenosis, mitral plasty, septal myectomy

\section{Introduction}

Hypertrophic cardiomyopathy (HCM) is defined as asymmetric (predominantly septal) left ventricular (LV) hypertrophy, of genetic origin, inconsistently associated with ejection obstruction (obstructive hypertrophic cardiomyopathy or OHCM). Excluded from the HCM setting are all valvular, arterial or systemic diseases that may result in an increase in LV mass.

It is a common cause of sudden death in young patients that may be the first manifestation [1]. It can classically associate with mitral insufficiency but its association with a mitral stenosis is very rare and the prognosis is reserved [2].

\section{Case report}

A 22-month-old child from an apparently healthy couple whose parents and other family members had no specific medical history was hospitalized at our center for a congestive heart failure syndrome. The clinical evaluation noted stage IV dyspnea, regular tachycardia at 150 beats / minute, quivering, and 4/6 aortic and mitral systolic murmur with preserved B2; accentuated pulmonary component of the

(C)2019 The Authors. Published by the JScholar under the terms of the Creative Commons Attribution License http://creativecommons.org/licenses/by/3.0/, which loize.marechal@umontreal.ca

maximilien.laviolette-brassard@umontreal.ca second heart sound. SPO2 was $100 \%$, with polypnea at 30 cycles / min and crackles at both lung. Painfull hepatomegaly to two fingers was noted.

The electrocardiogram recorded sinus tachycardia at 153 beats / $\mathrm{min}$, right ventricular hypertrophy, axis 130 - (figure 1). The chest X-ray showed cardiomegaly with a cardio-thoracic index: 0.63 , a supra-diaphragmatic tip, an accentuation, and vascular redistribution to the apices (figure 2).

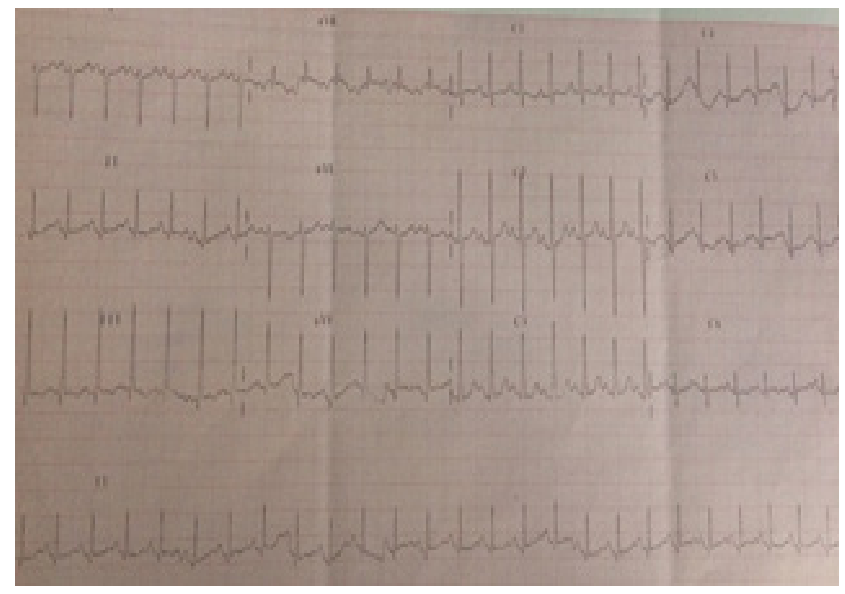

Figure 1: Electro cardiogram showing right 

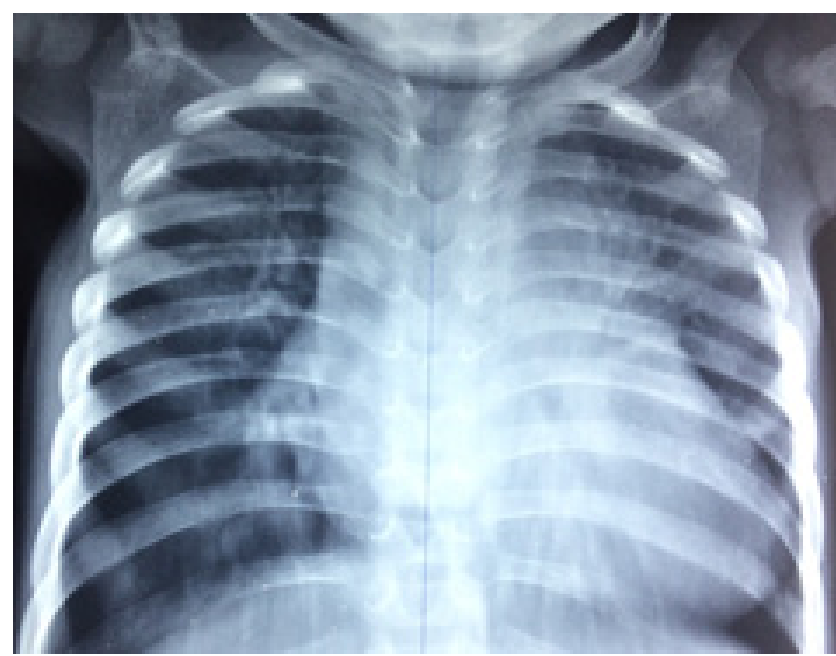

Figure 2: Chest X-ray showing cardiomegaly at the Ventricular hypertrophy expense of right cavities and vascular redistribution to the apices.

Doppler echocardiography showed sever congenital mitral stenosis (mean gradient: $27 \mathrm{mmHg}$ ) by abutment-commissure fusion (Image 3). No mitral leak associated.

There was no hypoplasia of the ring or supra-mitral membrane. There was concentric ventricular hypertrophy of the ventricle (septal thickness: $10 \mathrm{~mm}$, posterior wall thickness: $11 \mathrm{~mm}$ ) left responsible for a reduction of the ventricular cavity (Image 1) and SAM severe aortic stenosis (mean gradient: $73 \mathrm{mmHg}$ ). The aortic ring was hypoplastic $7 \mathrm{~mm}$ (Image 2). There was also hypertrophy of the right ventricle and moderate tricuspid regurgitation estimating pulmonary pressure at $79 \mathrm{mmHg}$.

While waiting for surgery, a medical treatment with propranolol was initiated.

While waiting for a possible transfer abroad for surgery, the patient died of sepsis in a context of gastroenteritis. The family investigation is ongoing looking for a genetic cause.

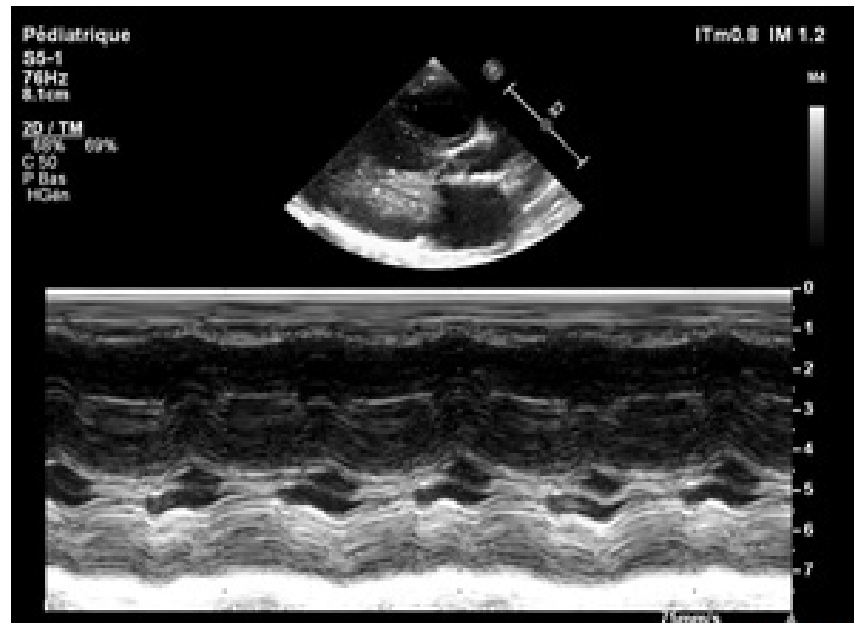

Image 1: M-mode para-sternal long axis view revealing

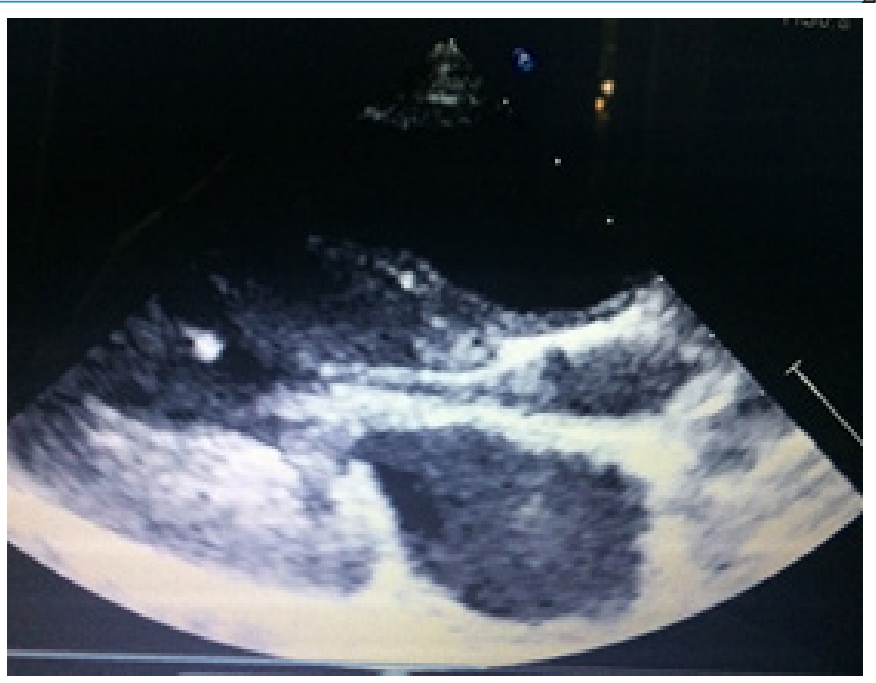

Image 2: shows concentric left ventricular hypertrophy and small aortic ring.

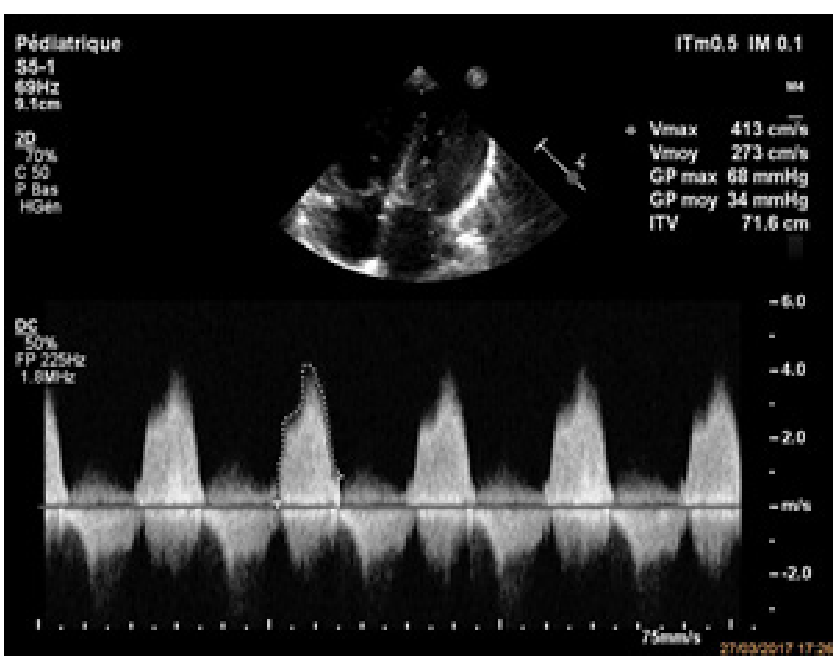

Image 3: Continuous wave Doppler on the mitral valve evaluating the elevation of the mitral gradient.

\section{Discussion}

The unusual presentation of our case is interesting because of its rarity and complexity of diagnosis and management. It is classic to find mitral regurgitation in hypertrophic cardiomyopathy. There is a "systolic anterior motion" (SAM) that creates a mitral leak and participates in aortic obstruction [2]. On the other hand, it is rare that hypertrophic cardiomyopathy is associated, as in our case, with mitral congenital valve stenosis.

Clinically, the patient may remain asymptomatic or have non-specific clinical signs. Sudden death may be the first manifestation [1]. We had observed a congestive heart failure syndrome with an episode of acute decompensation. This clinical presentation and pulmonary edema observed in our case are attributable to the sum of the physiopathological 
effects of obstructive hypertrophic cardiomyopathy and mitral stenosis. OHCM increased left ventricular end-diastolic pressure with anterograde airway obstruction resulting in upstream pressure elevation, while mitral stenosis caused dyspnea due to the left ventricular filling obstruction, thereby determining high pressure of the left atrium and pulmonary capillaries.

Transthoracic echocardiography revealed concentric hypertrophy of the left ventricle responsible for ventricular cavity reduction and SAM-tight aortic stenosis (mean gradient: $73 \mathrm{mmHg}$ ). We also noticed a small aortic ring. There was a high trans mitral gradient created by congenital mitral stenosis (mean gradient: $27 \mathrm{mmHg}$ ). The mechanism of mitral stenosis was particular and complex. If SAM was at least partly responsible for mitral stenosis; there was also a commissural fusion. There was no associated mitral regurgitation despite the presence of SAM. We did not report hypoplasia of the ring or supra-mitral membrane. Mitral stenosis had determined a severe pulmonary hypertension estimated by tricuspid regurgitation at $79 \mathrm{mmHg}$. The right ventricle was therefore hypertrophied. There were no other associated malformations such as aortic coarctation that could define the Shone complex [3, 4]. Even though we know that there are incomplete forms; the lesions described above did not seem to support any form of Shone complex.

Medical treatment with beta blockers or disopyramide is often beneficial in MHC [5].

Thus, our patient was on propranolol at the initial dose of $0.5 \mathrm{mg} / \mathrm{kg} /$ day. the dose was gradually increased to $3 \mathrm{mg} / \mathrm{kg} /$ day. the child was also treated with lasilix 2 $\mathrm{mg} / \mathrm{kg} /$ day and spironolactone $2 \mathrm{mg} / \mathrm{kg} /$ day because of the congestive heart failure. The evolution under this drug treatment was marked by the improvement of the congestion. It is usual to offer an invasive treatment in patients who are refractory to medical treatment. Thus, septal alcoholic ablation may result in a significant reduction in obstruction and septal thickness [6]. This method is often proposed in elderly patients at high surgical risk. We had not considered carrying it out in our patient mainly because of the existence of an associated mitral obstruction. We also did not consider percutaneous mitral dilatation since the mechanism of the stenosis was not a commissural fusion. Surgery has been shown to have the best results in the long term with low morbidity and mortality [7]. In most cases, this is a conventional myomectomy [8]. In some cases, this intervention is sufficient.
However, the myomectomy may be insufficient and it is conventional to perform a mitral valve plasty or mitral valve replacement to remove the mitral obstacle [8]. In our patient, we planned to perform a myomectomy associated with a mitral plasty. However, waiting for a possible transfer abroad for surgery; the patient died of sepsis in a context of gastroenteritis.

\section{Conclusion}

Hypertrophic cardiomyopathy can exceptionally be associated with congenital mitral stenosis as was the case in our patient with a rather atypical clinical presentation. Diagnosis should be made by Doppler echocardiography and treatment discussed collegially with cardiac surgeons. Surgery should consist of myomectomy and mitral plasty for those patients with hypertrophic cardiomyopathy associated with mitral stenosis. 


\section{References}

1. Maron BJ, Olivotto I, Spirito P (2000) Epidemiology of hypertrophic cardiomyopathy related death: revisited in a large non-referral-based patient population. Circulation 102:858-864.

2. Cavalcante JL, Barboza JS, Lever HM (2012) Diversity of mitral valve abnormalities in obstructive hypertrophic cardiomyopathy. Prog Cardiovasc Dis 54:517-522.

3. Shone JD, Sellers RD, Anderson RC, et al. (1963) The developmental complex of "parachute mitral valve," supravalvular ring of left atrium, subaortic stenosis, and coarctation of aorta. Am J Cardiol 11:714-725.

4. Bolling SF, Iannettoni MD, Dick M 2nd, et al. (1990) Shone's anomaly: operative results and late outcome. Ann Thorac Surg 49:887-893.

5. Nishimura RA, Holmes DR (2004) Hypertrophic obstructive cardiomyopathy. N Engl J Med 350:1320-1327.

6. Yavuzgil O, Tülüce K, Şimşek E, et al. (2012) Septal alcohol ablation in hypertrophic obstructive cardiomyopathy: A retrospective review. Turk Gogus Heart Checkers 20:427-433.

7. Ünal EU, Özen A, İșcan HZ, et al. (2012). Turk GogusKalpDama, 20: 421-426

8. Mataracı İ, Polat A, Songur ÇM, et al. (2009) Hypertrophic obstructive cardiomyopathy. Turk GogusKalpDama 17: 243-248.

Submit your manuscript to a JScholar journal and benefit from:

- Convenient online submission

ब Rigorous peer review

I Immediate publication on acceptance

ब Open access: articles freely available online

ब High visibility within the field

I Better discount for your subsequent articles Submit your manuscript at http://www.jscholaronline.org/submit-manuscript.php 